\title{
Assessment of Nutritional Status of School Going Children in Gujarat
}

\author{
Prerna P. Patel ${ }^{1,2^{*}}$, Pinal A. Patel ${ }^{1,2}$, Bhrugu Yagnik ${ }^{4}$, Khevna Vora ${ }^{5}$, Anshika Verma ${ }^{5}$, Ashish D. Patel ${ }^{1}$, \\ Shashi A. Chiplonkar ${ }^{3}$, Anuradha V. Khadilkar ${ }^{3}$ \\ ${ }^{1}$ Department of Biotechnology, Hemchandracharya North Gujarat University, Patan-384265, Gujarat, India \\ ${ }^{2}$ Department of Biochemistry and Biotechnology, Khyati Institute of Science, Khyati Foundation, Ahmedabad-380058, Gujarat, \\ India \\ ${ }^{3}$ Hirabai Cowasji Jehangir Medical Research Institute, Jehangir Hospital, 32, Sassoon Road, Pune-411001, Maharashtra, India \\ ${ }^{4}$ Department of Biochemistry, The Maharaja Sayajirao University of Baroda, Vadodara-390002, Gujarat, India \\ ${ }^{5}$ Department of Biochemistry, M G. Science Institute, Ahmedabad-380009, Gujarat, India
}

*Corresponding author: Prerna Patel, Principal Investigator and Women Scientist Scheme (WOS-A), Department of Biotechnology, Hemchandracharya North Gujarat University, Patan - 384265, Gujarat, India, Tel: +91-9724305528;

E-mail: prernappatel@gmail.com

\begin{abstract}
Objectives: To evaluate the nutritional health status of school going children in Gujarat Methods: A cross-sectional study on apparently healthy adolescents (10 - 14 years, $\mathrm{n}=604$ ) from different SES, was conducted in Gujarat, Western India. The outcome parameters included anthropometric measures, body composition, and serum $25 \mathrm{OHD}$ and haemoglobin concentrations (in sub-sample). Chi-square test was used to estimate the percentage prevalence of stunting, wasting, \% fat mass (FM), vitamin D status and anaemia amongst school going children.
\end{abstract}

Results: Girls were significantly taller and heavier than boys and also had significantly increased fat mass (FM) and bone mineral content (BMC) whereas boys had significantly increased muscle mass (MM) and fat free mass (FFM). $9 \%$ of both boys and girls showed wasting whereas $9 \%$ of the boys and $6 \%$ of the girls were at the risk of being overweight $(\mathrm{p}>0.05)$. Similarly $10 \%$ boys and $7 \%$ girls were stunted and $31 \%$ boys and $21 \%$ girls had subnormal height $(\mathrm{p}<0.05) .63 \%$ boys and $43 \%$ girls were underfat; in contrast, $8 \%$ boys and $6 \%$ girls were overfat and $10 \%$ boys and $5 \%$ girls were obese $(\mathrm{p}<0.05)$. We found a high prevalence of hypovitaminosis D, 34\% boys and $30 \%$ girls had insufficient (between $20 \mathrm{ng} / \mathrm{ml}$ to $30 \mathrm{ng} / \mathrm{ml}$ ) and $60 \%$ boys and $69 \%$ girls had deficient $(<20 \mathrm{ng} / \mathrm{ml})$ serum $25 \mathrm{OHD}$ concentration. One fifth of the study population was suffering from mild/moderate anaemia.

Conclusion: Stunting and underfat were observed more often in boys as compared to girls. There exists a high prevalence of hypovitaminosis D in adolescents of Gujarat.
Received Date: November 20, 2016

Accepted Date: November 25, 2016

Published Date: November 28, 2016

Citation: Patel, P.P., et al. Assessment of Nutritional Status of School Going Children in Gujarat. (2016) Int J Food Nutr Sci 3(2): $378-380$.

DOI: $10.15436 / 2377-0619.16 .1231$

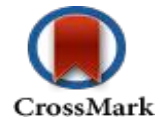

\section{Introduction}

Nutritional Status is defined as the condition of health of an individual as influenced by the nutrient intake and utilization in the body. A majority of adolescents in India suffer from nutritional deficiencies. Good nutrition is significant to meet the deficiencies that occurred during childhood so as to make up for the demand of growth and development, provision of sufficient stores of energy for illnesses, and prevent onset of nutrition-as- sociated diseases in adulthood ${ }^{[1]}$. Furthermore, anthropometric measurements and body composition can be used for early diagnosis of nutrient deficiencies or inadequate nutrient intake. This can further aid to improve nutritional status through a nutrition plan before the disease occurs.

Adolescence is marked by peak bone mass accrual ${ }^{[2]}$; during which vitamin D deficiency may become the cause for producing devastating skeletal manifestations by limiting bone accretion during the growth phase ${ }^{[3]}$. Rapid growth during ado- 
lescence accounts for an increased iron supplies due to increase in blood volume, red blood cell mass and lean body mass that increases iron requirements for haemoglobin in blood and myoglobin in muscles. Iron deficiency causes anaemia. A high frequency of iron deficiency anaemia is observed in adolescents in the WHO South East Asia Region ${ }^{[1]}$. Though adolescents make up a very large part of our population, there exists scarcity of data on health of Indian adolescents; hence it is a significant public health problem. Our study aims on evaluating the nutritional health status of school going children in Gujarat.

\section{Materials and Methods}

A cross sectional study in school going adolescents aged 10 to 14 years from urban and semi urban regions of Gujarat, Western India, was conducted from January 2012 to March 2014, to evaluate their nutritional status.

\section{Study subjects}

Study subjects consisted of a total of 604 adolescents (302 boys) selected randomly from four private schools and two municipal schools. The purpose of the study was explained to the administrative authorities, principal, teachers, adolescents and their parents. An informed written consent was obtained from the school authorities and parents; an assent was obtained from the adolescents. Adolescents and parents were interviewed for filling up a screening questionnaire.

To confirm the SES of the participants, stratification of adolescents into high, middle and low SES was performed according to the modified Kuppuswamy's socioeconomic status scale that takes into account the education, occupation, and family income ${ }^{[4]}$. Inclusion criteria were apparently healthy adolescents in the age group of 10 to 14 years. Participants with any chronic ailment or congenital diseases that may affect their health status were excluded from the study.

The selection of participants was performed using computerized random number generation. Ethical approval was granted by the Ethics Committee of Gujarat Medical Education \& Research Society (GMERS) General Hospital, Gandhinagar, Gujarat (ECR/535/Inst/GJ/2014).

\section{Anthropometry and body composition}

Standing height was measured to the nearest $1 \mathrm{~mm}$, using a stadiometer (Leicester height meter, Child growth foundation, UK, range $60-207 \mathrm{~cm}$ ). Weight (measured to nearest of $0.1 \mathrm{Kg}$ ) and body composition [Fat mass (FM), Muscle mass (MM) and Fat free mass (FFM)] was determined using Bioelectrical Impedance Analysis (BIA) on a high capacity body composition monitor (SC240 MA, Tanita, India). Bone mineral content (BMC) was calculated by deducting FM from FFM. Height, weight, and body mass index (BMI) $\mathrm{Z}$ scores were computed using ethnic specific data ${ }^{[5]}$.

\section{Biochemical estimation}

In a sub-population $(\mathrm{n}=180)$, serum 25 , hydroxyvitamin D3 (25OHD) concentrations were measured by chemiluminescent microparticle immunoassay (CMIA) (Abbott, Architect, India; Coefficient of variance $3.7-0.7 \%$ ) and haemoglobin concentrations were measured by cyanmethemoglobin method (differential lysis with Beckman coulter principle; Coefficient of variance $=1.5 \%$ ).

\section{Statistical analysis}

Descriptive characteristics (mean and standard deviations) were calculated for anthropometric measures and body composition in boys and girls. Student's t-test was used to test the differences in subject characteristics. Chi-square test was used to estimate the percentage prevalence of stunting, wasting, $\%$ fat mass (FM), vitamin D status and anaemia amongst school going children. The analysis was stratified for gender. All analysis was performed using SPSS version 18.0 and the statistical significance level was set at $\mathrm{p}<0.05$.

\section{Results and Discussion}

A total of 604 subjects (302 boys) were studied from 10 to 14 years with mean age of $11.7 \pm 1.1$ years. Table 1 summarizes the characteristics (mean $\pm \mathrm{SD}$ ) for the study population stratified by gender. Growth and body composition serves as a significant indicator of nutritional status. We found that girls were significantly taller and heavier than boys as judged by their HAZ and WAZ. Girls also had significantly increased fat mass (FM) and bone mineral content (BMC) whereas boys had significantly increased muscle mass (MM) and fat free mass (FFM). 9\% of both boys and girls showed wasting as judged by their WAZ whereas $9 \%$ of the boys and $6 \%$ of the girls were at the risk of being overweight $(\mathrm{p}>0.05)$. Similarly $10 \%$ boys and $7 \%$ girls were stunted and $31 \%$ boys and $21 \%$ girls had subnormal height as judged by their HAZ $(\mathrm{p}<0.05)$.

Table 1: Descriptive characteristics of school going boys and girls from Gujarat, India.

\begin{tabular}{|l|c|c|}
\hline Variables & Boys $(\mathbf{n}=\mathbf{3 0 2})$ & Girls $(\mathbf{n}=\mathbf{3 0 2})$ \\
\hline Age (years) & $12.3 \pm 1.1$ & $12.1 \pm 1.1$ \\
\hline Height (cms.) & $145.7 \pm 9.6$ & $145.6 \pm 8.5$ \\
\hline Weight (kg) & $35.5 \pm 10.4$ & $35.6 \pm 9.1$ \\
\hline BMI (kg/m $)$ & $16.4 \pm 3.3$ & $16.6 \pm 3$ \\
\hline HAZ (\% stunted) & $-0.6 \pm 1.1 *(10 \%)$ & $-0.4 \pm 1.1(7 \%)$ \\
\hline WAZ & $-0.9 \pm 1.2 *$ & $-0.7 \pm 1.1$ \\
\hline BAZ (\% wasted) & $-0.8 \pm 1(9 \%)$ & $-0.7 \pm 1(9 \%)$ \\
\hline$\%$ FM (\% underfat) & $12.3 \pm 10.4 *(63 \%)$ & $18.9 \pm 8.1(43 \%)$ \\
\hline \% MM & $83.4 \pm 10^{*}$ & $76.7 \pm 7.8$ \\
\hline \% BMC & $4.3 \pm 0.5^{*}$ & $4.4 \pm 0.3$ \\
\hline \%FFM & $87.7 \pm 10.4 *$ & $81.1 \pm 8.1$ \\
\hline
\end{tabular}

HAZ, Height for age Z score; WAZ, Weight for age Z score; BAZ, BMI for age $Z$ score; All values are mean $\pm \mathrm{SD}$

* Mean value is significantly different between Boys and Girls ( $\mathrm{p}<$ $0.05)$.

Comparing with the prevalence cut-off values for public health significance provided by $\mathrm{WHO}$, the percentage of stunted boys and girls fell under the category of low prevalence $(<20 \%)$; however, the percentage of wasted adolescents fell under poor category $(5-9 \%)^{[6]}$.

Examining the body composition, \% FM of the study population was compared with the reference body fat centile cutoffs $\left(2^{\text {nd }}, 85^{\text {th }}\right.$ and $95^{\text {th }}$ centiles defined the cut-offs for underfat, overfat and obese) and body fat status was evaluated. We found that $63 \%$ boys and $43 \%$ girls were underfat; in contrast, $8 \%$ boys and $6 \%$ girls were overfat and $10 \%$ boys and $5 \%$ girls were obese $(\mathrm{p}<0.05)$. 


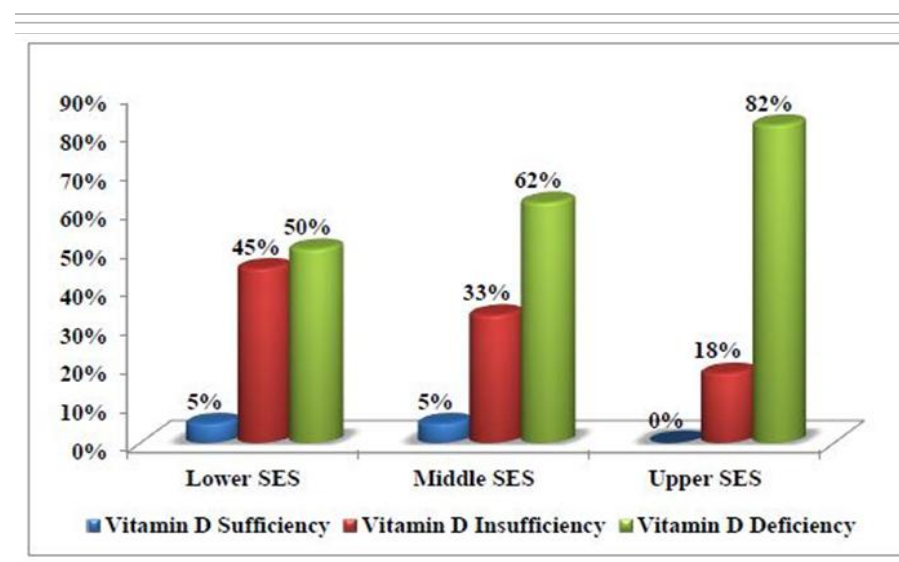

Figure 1: Vitamin D Status of School going children from lower, middle and upper Socioeconomic strata (SES) of Gujarat, India $(p<0.05)$.

Vitamin D exerts a direct influence on skeletal growth of the children by mediating increased calcium absorption and retention in bones. Thus, we also examined the vitamin $\mathrm{D}$ status in our study population. We found a high prevalence of hypovitaminosis D i.e. deficiency of vitamin D in our study participants. Only $6 \%$ boys and $1 \%$ girls had sufficient $(>30 \mathrm{ng} / \mathrm{ml}$ ) serum $25 \mathrm{OHD}$ concentration, whereas $34 \%$ boys and $30 \%$ girls had insufficient (between $20 \mathrm{ng} / \mathrm{ml}$ to $30 \mathrm{ng} / \mathrm{ml}$ ) and $60 \%$ boys and $69 \%$ girls had deficient $(<20 \mathrm{ng} / \mathrm{ml})$ serum $250 H D$ concentration. Severe vitamin D deficiency as observed in our study population has also been reported by others ${ }^{[7,8]}$. Further examining vitamin D status in different socioeconomic strata (SES), classified as per Kuppuswamy classification, we found that adolescents from upper SES had significantly less serum 25OHD concentration compared to middle and lower SES $(p<0.05)$.

Upper SES adolescents were the most affected with a majority of the adolescents suffering from hypovitaminosis D; none of them had sufficient vitamin D concentration, $82 \%$ of them were deficient and 18\% were insufficient for serum 25OHD concentration $^{[9]}$. Amongst lower SES adolescents, 50\% of them were deficient while $45 \%$ had insufficient and $5 \%$ had sufficient serum $25 \mathrm{OHD}$ concentration. Similarly, amongst middle SES, $62 \%$ were deficient while $33 \%$ were insufficient and $5 \%$ of the adolescents were sufficient for serum 25OHD concentration.

Anaemia also shows a significant negative impact on growth and development. Other research also documents that more than $50 \%$ children suffer from iron deficiency anaemia ${ }^{[1]}$. Our study also emphasizes that $14 \%$ boys (17\% from lower SES, $20 \%$ from middle SES and $6 \%$ from upper SES) and $12 \%$ girls (23\% from lower SES, 10\% from middle SES and 3\% from upper SES) suffered from mild anaemia whereas $5 \%$ boys $(10 \%$ from lower SES, 3\% from middle SES and 3\% from upper SES) and $10 \%$ girls ( $7 \%$ from lower SES, $13 \%$ from middle SES and $10 \%$ from upper SES) suffered from moderate anaemia $(\mathrm{p}>$ $0.05)$. Overall, one fifth of the study population was suffering from mild/moderate anaemia. Comparing with the prevalence cut-off values for public health significance provided by WHO, the prevalence of anaemia would be considered as a moderate public health problem $(20-39.9 \%)^{[6]}$.

\section{Conclusion}

Stunting and underfat were observed more often in boys as compared to girls. There exists a high prevalence of hypovitaminosis D where two-third of the school going children were deficient and one-third of them were insufficient for vitamin D. There is an urgent need to create nutritional awareness programmes emphasizing vitamin $\mathrm{D}$ deficiency along with initiating supplementation programmes to overcome it.

\section{Funding}

This work was financially supported by Women Scientist Scheme-A (WOS-A), Department of Science and Technology (DST), Ministry of Science and Technology, New Delhi, India; Project no: SR-WOS-A-LS-178-2010.

\section{Competing Interests: None declared.}

Ethical Approval: Ethical approval was granted by the Ethics Committee of Gujarat Medical Education \& Research Society (GMERS) General Hospital, Gandhinagar, Gujarat, India.

\section{References}

1. WHO. (2006) Adolescent Nutrition: A Review of the Situation in Selected South-East Asian Countries.

2. Patel, P., Mughal, M.Z., Patel, P., et al. Dietary calcium intake influences the relationship between serum 25-hydroxyvitamin D3 (25OHD) concentration and parathyroid hormone (PTH) concentration. (2016) Arch Dis Child 101(4): 316-319.

3. Ross, C., Caballero, B., Cousins, R.J., et al. Modern Nutrition in Health and Disease. Eleventh. Ross CA, Caballero B, Cousins RJ, Tucker KL, Ziegler TR, editors. (2014) Wolters Kluver, Lppincott Williams and Wilkins 1646-1646.

4. Ravikumar, B.P., Dudala, S.R., Rao, A.R. Kuppuswamy's Socio-economic Status-A Revision of Economic Parameter for 2012. (2013) Int J Res Dev Heal: 1(1): 2-4.

5. Khadilkar, V.V., Khadilkar, A.V., Cole, T.J et al. Crosssectional growth curves for height, weight and body mass index for affluent Indian children, 2007. (2009) Indian Pediatr 46(6): 477-489.

6. WHO NLIS. Nutrition Landscape Information System, Country Profile Indicators (2010) Interpretation Guide.

7. Marwaha, R.K., Tandon, N., Reddy, D., et al. Vitamin D and bone mineral density status of healthy schoolchildren in northern India. (2005) Am J Clin Nutr 82(1): 477-482.

8. Khadilkar, A.V. Vitamin D Deficiency in Indian Adolescents. (2010) Indian Pediatr 47(9): 103-106.

9. Holick, M.F., Chen, T.C. Vitamin D deficiency: a worldwide problem with health consequences. (2008) Am J Clin Nutr 87(4): 1080S-1086S.
Online ISSN: $2377-0619$

Journal Title: International Journal Food and Nutritional Science Journal Short Name: Int J Food Nutr Sci
Ommega Online Publishers

E-mail: foodscience@ommegaonline.org

Website: www.ommegaonline.org 